\title{
Why I . . . run
}

\section{Consultant psychiatrist and clinical director Derek Tracy talks to Helen Jones about how running helps his mental health}

\section{Helen Jones}

The BMJ

"When you start running, zero to five km are hard to accomplish," says Derek Tracy. "Once you get your body adjusted and used to that, running anything from five to $20 \mathrm{~km}$ is so much easier."

Tracy runs two or three times a week with a main run of between 20 and $25 \mathrm{~km}$ interspersed with shorter runs of five to $10 \mathrm{~km}$. He admits, however, that when he first began running as a new dad in his early thirties it was tough.

"I sensed that I needed to do something to find a way of coping with my hectic life and to get fit," he says. "The first time I went out, I ran about 500 metres and came back feeling miserable-my legs hurt and my lungs hurt-but I pressed through it and it's something I've come to love."

Tracy says that as well as physical benefits, regular running has improved his mental health. "I didn't initially appreciate the impact it would have but, even now, if I've had a busy week the one thing that will blow away the stress is a quick run. It will just clear my head."

$\mathrm{He}$ added, "On a long run, for the first one or two $\mathrm{km} \mathrm{I} \mathrm{can} \mathrm{feel}$ lots of thoughts jumbling around in my head and as I go beyond $5 \mathrm{~km}$ it becomes meditative. I feel myself settle down and the worries disappear. It's just incredible for our mental health and I would recommend it to everyone."

Tracy always runs outdoors. "I cannot stand being on a treadmill. I feel like a rat in a cage," he says. "I live in east London and run along the Thames or Regent's Canal. I love to see the outdoor life and run past the houseboats and the gas works where there's a kind of urban beauty that changes with the seasons. I'm a silent runner; I don't listen to music, it ruins it a bit for me. I like to listen to the canal and the leaves in the trees," he says.
Tracy does occasionally run competitively, mainly half marathons. "I'll do it about twice a year just to test myself, but the thing I love about running is that the competition is only ever with yourself and not with other people. It's about seeing what time I can do."

His greatest joy, he says, is being out with his 12 year old son. "He cycles alongside me and sometimes runs-we'll run for a bit and then walk for a bit. It's wonderful," he says. "There are no gadgets, no Xbox, and no TV. We chat and it's a very special time. I don't think he realises it's a special time, but he tells me about school and about his friends and asks me about when I was a boy. I just love it."

\section{How to make the change}

- Try to go with someone else so that you can motivate each other. It's harder to avoid going for a run if someone else is expecting you to turn up

- Start slowly, alternating walking and running

- Try a running programme such as the NHS's Couch to $5 \mathrm{~K}$, a nine week guided plan

- If you want to run with others, try Parkrun which organises weekly $5 \mathrm{~km}$ timed runs in parks across the country free of charge. www.parkrun. org.uk/register

This interview was conducted in January. Since then Derek has found that running has become both more important for sustaining wellbeing in these exceptional times, and more of a challenge in trying to find sensible routes and times to minimise proximity to others. He has found very early morning runs to be one way around this.

Published by the BMJ Publishing Group Limited. For permission to use (where not already granted under a licence) please go to http://group.bmj.com/group/rights-licensing/ permissions 